\title{
Design of a Software Tool Supporting Orientation in the Context of Digital Transformation
}

\author{
Torsten Gollhardt \\ University of Muenster - ERCIS \\ gollhardt@ercis.de
}

\author{
Andreas Hermann \\ University of Muenster - ERCIS \\ hermann@ercis.de
}

\author{
Ann-Kristin Cordes \\ University of Muenster - ERCIS \\ cordes@ercis.de
}

\author{
Benjamin Barann \\ University of Muenster - ERCIS \\ barann@ercis.de
}

\author{
Paul Kruse \\ University of Muenster - ERCIS \\ kruse@ercis.de
}

\begin{abstract}
The digital transformation is a continuous and complex but indispensable endeavor. Because practice and academia regularly develop new digital technologies, companies face difficulties in selecting appropriate technologies to innovate their business model. Step-by-step instructions may guide companies to identify, evaluate, and select potential digitalization ideas. Software tools can support these activities in a structured way. Thus, the research objective of this paper is to design a software tool supporting the orientation phase of a company's digital transformation. To reach this objective, we conduct an action design research approach in cooperation with three companies. As an evaluation step, a focus group discussion with practitioners and end-users is carried out. The final tool design comprises 18 design principles that serve as the basis for a set of visual mockups and a prototype implementation of the intended tool.

Index Terms-Digital Transformation, Idea Management, Action Design Research, Design Principle, Software Design
\end{abstract}

\section{INTRODUCTION}

The Digital Transformation (DT) is omnipresent. It is changing the way we live, what we think, what we want, and how companies monetize this [1]. As a result, companies must transform their business to avoid becoming yet another company that has missed its DT [2], [3]. As an enterprise, it is difficult to utilize new technologies or technology-enabled practices to stay competitive [4]-[6]. In line with this, the identification, evaluation, and selection of feasible ideas to innovate a company's business model becomes a substantial challenge in the DT.

To support these activities, practice and academia developed various procedure models that guide organizations in their DT through a sequence of relevant steps [7]-[9]. For instance, Barann et al. [7] propose a procedure model wrapping the complexity of the DT "into manageable and easily understood action items". This procedure model comprises two main phases: orientation and iterative transformation [7]. The DT's orientation phase requires a careful assessment and selection of a portfolio of possible digitalization ideas [7], [10].

The orientation phase can be seen as a pre-implementation stage, which is concerned with initiating an organization's DT efforts in terms of investigating its as-is situation as well as engaging in the identification, evaluation, and prioritiza- tion of digitalization ideas. This phase, however, is often characterized by uncertainties, intuitions, little structure, and a rapidly changing context [7], [11], [12]. Indeed, smaller companies, in particular, perceive establishing a well-defined DT strategy as less feasible [13]. To provide a remedy, research and practice have proposed tools that aim at overcoming the challenges of this orientation phase and aid in developing a DT strategy [14]-[16]. Most of those propositions, though, are relatively static and do not account for the constant technological and environmental change, which mirrors the dynamic nature underlying the DT [17]-[19]. In fact, there exists the explicit need for tools to integrate dynamic aspects, which are currently underrepresented in those [15], [20]. For instance, dedicated roadmapping tools could support essential idea management tasks (i.e., the identification, evaluation, and selection of digitalization ideas) to provide structure in the orientation phase of a company's DT (cf. [21]). The success of organizations' DT initiatives is vitally dependent on the effective management of ideas in this orientation phase [22], [23]. Supporting idea management activities with (ITsupported) tools can highly reduce the complexity of these and, thereby, increase their effectiveness [11], [22], [24].

Thus, the research objective of this paper is to design a software tool supporting the orientation phase of a company's DT. To reach this objective, an Action Design Research (ADR) approach according to Sein et al. [25] is followed along with three anonymized case projects, which applied the orientation phase of the procedure model by Barann et al. [7] in practice. The choice for this procedure is motivated twofold. First, the model is based on an initial focus group discussion with 30 experts from different domains, which informs the model's design and accounts for a practical embedding and high practical relevance. Second, as Barann et al. [7] synthesized existing procedure models for supporting the DT in organizations, the model's scope in terms of describing the process of DT is assumed to be sufficiently high. Overall, the model turned out to be useful to design the proposed software tool.

Although the chosen procedure model considers support from external innovation units and the case projects have been implemented in local small and medium-sized enterprises 
(SMEs), we are confident that the tool design is generalizable beyond the SME sphere. The resulting design of the tool comprises a list of empirically derived and theoretically validated Design Principles (DPs) informing the software tool's core requirements as well as a set of visual mockups and an implemented software prototype. The list of DPs can be considered as meta-artifact (cf. [26]) representing the prescriptive design knowledge regarding the intended IT-artifact [27].

The IT-artifact integrates existing concepts of idea management and DT into a web application. More specifically, the tool aims at managing digitalization ideas (i.e., identification, evaluation, selection) in the context of preparing DT initiatives in a structured way. The software tool is designed to be used in on-site, collaborative workshop settings. Designated users of the tool are, e.g., decision-makers, consultants, or employees in charge of digitalization initiatives who seek guidance in DT. This is a typical design-oriented contribution in accordance with Hevner [28]. The main contribution of our work is an exaptation since we transfer proper solutions from other domains to the problem space of DT (cf. [29]). The developed artifacts represent the exaptation as knowledge contribution, i.e., the design of the software tool. Furthermore, we shed light on how to design supporting software tools in the context of DT. By applying the ADR approach involving several experts from practice and a hermeneutic literature review, we strengthen the theoretical and practical evidence.

The remainder of the paper is structured as follows: In the next section, the research background with respect to DT, idea management, and business model research is introduced. Section III illustrates the research method. Next, the set of DPs is proposed (see Section IV and, afterward, evaluated and refined in Section $\mathrm{V}$. Based on these refinements, we demonstrate a tool prototype in Section VI In Section VII we discuss the tool design as well as the performed ADR approach. Finally, the paper concludes in Section VIII.

\section{RESEARCH BACKGROUND}

\section{A. Digital Transformation \& Idea Management}

DT is an organization's “continuous [and] complex undertaking" [30] aiming at its iterative digitalization improving existing processes and the implementation of digital practices in the business model, i.e., digital innovation [31]. In other words, in line with Wiesböck and Hess [32] and inspired by the work of Vandenbosch et al. [33], we consider digital innovation as "the successful implementation of a (creative) idea" [33] that can manifest as new (digital) practices applied to the business model [33], [34]. Besides, following Berger et al. [35], digital practices (i.e., approach) and digital technologies (i.e., component) can be distinguished as different technology layers [35]. Accordingly, digital practices are realized through digital technologies. Thus, DT can also be seen as "a process that aims to improve an entity by triggering significant changes to its properties through combinations of [...] [digital] technologies" [17].

The term technology aggregates human-made techniques, tools, materials, and sources of power accomplishing a spe- cific purpose [36]. Technology can have various intended and unintended impacts on users' routines [37]. It is also a source of business model innovation and capable of shaping (new) business models [38]. Foss and Saebi [39] define business model innovation as "designed, novel, nontrivial changes to the key elements of a firm's business model and/or the architecture linking these elements". However, technology itself does not carry any intrinsic value contributing to the company's success until it is utilized beneficially [5]. Thus, companies need to be aware of the available technologies and their opportunities through technology-enabled digital practices for innovating their business model [4].

To obtain an overview of relevant innovation opportunities, companies are required to follow a series of activities, i.e., identifying, evaluating, and selecting the most promising ideas, which essentially describe the process of idea management [22]. The generic construct idea can be seen as the basic building block of any innovation [22]. Following the understanding that implementing (digital) innovations constitutes the main aspiration of DT, ideas represent an essential foundation in this context as well. The literature in this field focuses on aspects such as idea management in practical applications [11], [21], [33], idea management processes [40], or success factors in the context of idea management [22]. In the pursuit of designing a software tool supporting the effective management of ideas in the orientation phase of DT, the investigation of success factors regarding the activities identifying, evaluating, and selecting is of particular relevance [22]. In other words, the research realm on idea management provides a solid theoretical foundation for the design of the intended software tool.

\section{B. Guidance in the Context of the Digital Transformation}

DT is an ongoing, iterative process for which researchers have developed procedure models that guide organizations through a sequence of relevant steps [7], [30], [31], [41]. Existing procedures consider steps like idea identification, evaluation, and selection as well as experimentation, refinement, launch, monitoring, and controlling (e.g., [7]-[9], [42]). Overall, existing models serve different purposes and focus on various aspects of the DT. In general, a procedure model should cover an orientation phase, followed by an iterative transformation phase [7] to mirror the cyclic nature of DT [30]. This paper builds upon the ideas of the orientation phase as proposed by Barann et al. [7] by designing a software tool, which supports practitioners in this phase.

For the orientation phase, the procedure suggests positioning a company in the context of the DT first. Therefore, a planning team should be established, the current business model needs to be understood, the as-is situation needs to be analyzed, current digitalization topics need to be reviewed, and the company's digital maturity should be determined. Second, the procedure suggests creating a digitalization roadmap. This includes the generation of initial digitalization ideas, their alignment with the company's strategic goals, their evaluation in terms of expected outcomes \& feasibility, and the compilation of those ideas onto a digitalization roadmap [7]. 
Digitalization ideas, in this context, can be understood as hypothetical implementations of digital practices enabled by digital technologies [7], [33]. The actual implementation of the digitalization ideas from the roadmap would be part of the iterative transformation [7]. The resulting digital innovation can impact the business model on different levels [7], [43]. For instance, Wessel et al. [18] recently discussed IT-enabled organizational transformation as improving the existing value creation to better support the current value proposition and DT as redefining the organization's value proposition. Whether an organization performs one or the other is not defined within the orientation phase and will only be determined when a specific idea from the roadmap is implemented.

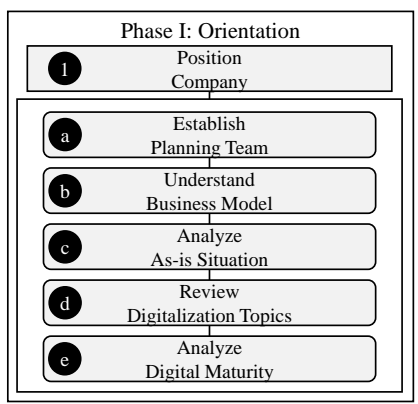

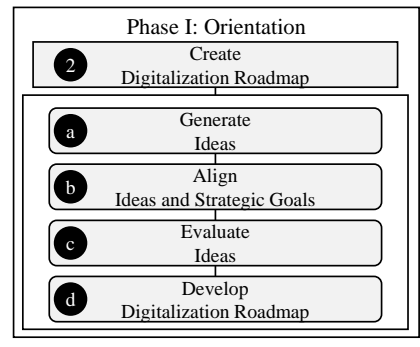

Fig. 1. Orientation in the context of the Digital Transformation (DT) following Barann et al. [7].

\section{Technology Roadmaps \& Business Model Tools}

In recent years, technology roadmaps have been combined with business model tools (cf. [16]) in various ways (e.g., [44][46]). A technology roadmap is a flexible technique to support technology and business strategy planning [45], [47]. In this context, Phaal et al. [47] emphasize the interrelation of both strategic subjects (i.e., technology and business) in order to sustain the company's success. Despite there is no commonly accepted technology roadmap type or methodology [44], [47], the concept technology roadmap structures and visualizes a range of elements grouped into different layers (e.g., technology, product, and market) along a particular timeline [47], [48]. Due to its flexibility, technology roadmaps can be applied for a plethora of strategic purposes [47], such as visualization for business model innovation [46], [49]. For instance, Schaller et al. [46] developed a business model innovation roadmapping canvas with three layers (i.e., activities, business model, and market) and four timeframes (i.e., initial situation, short-term, mid-term, and long-term). Thus, technology roadmaps are appropriate to compensate for the lack of dynamics in business model frameworks as they visualize the transition from current to future states [15], [20].

Following Schwarz and Legner [16], business model tools are boundary objects "[...] that are available to support decision-making about [business models] and enable interactions and collaboration between different actors" [16]. In the context of business model innovation, a business model needs to be documented and visualized in order to support its innovation in a meaningful way [50]. Hence, a variety of software tools have been proposed by practice and academia to support the development of business models [51], [52]. Similar to process modeling tools, business model development tools facilitate the creation and modification of business models by using a modeling language, i.e., visual notation and semantics [52]. A taxonomy classifying functions of business model development tools was created by Szopinski et al. [52] and later revised (cf. [15]). In total, 43 functions describe business model development tools in three meta-dimensions, i.e., modeling, collaboration, and technical [15]. Although concepts for technology roadmapping to support business model innovation already exist in the literature, Szopinski et al. [15] identified a lack of corresponding features in business model development tools as only one analyzed tool included related features [15].

\section{RESEARCH METHOD}

\section{A. Action Design Research}

Based on the research objective and the presented research background, the following research question is derived: How should a software tool be designed to support a company in the orientation phase of its DT? To answer this research question, the ADR method proposed by Sein et al. [25] is applied. By utilizing ADR, an IT-artifact like the intended software tool as well as the underlying list of DPs can be designed through the iterative building and evaluation of ensemble artifacts within an organizational setting [25], [53]. Following Chandra et al. [27] "design principles interpret descriptive, explanatory, and predictive knowledge - which can be referred to as the kernel theory-into something that can be used in the practice of building purposeful [IT] artifacts". Moreover, the ADR method has already been proven useful in related research. For instance, ADR has been applied to design a business model tool for data-driven business models [54], to develop DPs for virtual reality-based safety training [55], and to examine digital innovation projects in a similar project environment [56].

We performed the ADR method in three anonymized case projects (cf. Table I) with the aim of applying different tools to support and guide the practitioners in the early DT process. These projects have been implemented with a publicly-funded digital innovation unit (cf. [57]) as part of the German 'Mittelstand Digital' initiative (www.mittelstand-digital.de). The scope of the projects was the ideation and conceptualization of potential digital innovations (cf. [57], [58]). In all three case projects, the orientation phase of the procedure model by Barann et al. [7] was carried out, resulting in company-specific roadmaps orchestrating various digitalization ideas along a timeline.

In the projects, the iterative research cycles were driven by regular meetings and workshops, in which findings were presented and discussed. The overall research design follows the four stages and seven principles for applying an ADR approach by Sein et al. [25] described in the following. The goal of the performed ADR approach is to design a software artifact that supports companies during the orientation phase of their DT, as outlined in the procedure model by Barann et 
TABLE I

OVERVIEW OF THE CASE PROJECTS.

\begin{tabular}{llllll}
\hline$\#$ & Case Name & Firm Description & Employees & Project Goal & Project Outcome \\
\hline 1 & $\begin{array}{l}\text { Future } \\
\text { Retail }\end{array}$ & $\begin{array}{l}\text { Stationary retailer } \\
\text { for electronics }\end{array}$ & $45+$ & $\begin{array}{l}\text { Improve customer } \\
\text { communication }\end{array}$ & $\begin{array}{l}\text { Overview of the current digitalization status \& one roadmap, } \\
\text { including feasible and prioritized digitalization ideas }\end{array}$ \\
\hline 2 & $\begin{array}{l}\text { Smart } \\
\text { Container }\end{array}$ & $\begin{array}{l}\text { Manufacturer for } \\
\text { truck trailers }\end{array}$ & $200+$ & $\begin{array}{l}\text { Extend product/ } \\
\text { service portfolio }\end{array}$ & $\begin{array}{l}\text { Digitalization roadmap for digitizing container chassis \& } \\
\text { suggestions on how to realize related digitalization ideas }\end{array}$ \\
\hline 3 & $\begin{array}{l}\text { Future } \\
\text { Bike }\end{array}$ & $\begin{array}{l}\text { Manufacturer for } \\
\text { road bikes }\end{array}$ & $10+$ & $\begin{array}{l}\text { Increase customer- } \\
\text { centricity }\end{array}$ & $\begin{array}{l}\text { Digitalization roadmap, including digitalization ideas } \\
\text { \& one selected realized digital marketing concept }\end{array}$ \\
\hline
\end{tabular}

al. [7]. Moreover, the intended software tool is meant to guide and document workshops in the context of DT initiatives.

In the Problem Formulation stage, the problem was defined together with the industry partner from "Future Retail" to consider a practical problem [Principle 1: Practiceinspired Research]. In order to enrich the practical insights, we performed a hermeneutic literature review following Boell and Cecez-Kecmanovic [59] to identify the relevant publications in the research areas 'digital transformation', 'idea management', 'technology roadmaps', and 'business model tools'. The overall aim was to comprehend the underlying theoretical background that is necessary to successfully present a suitable solution to the problem and research objective at hand [Principle 2: Theory-ingrained Artifact].

During the stage of Building, Intervention, and Evaluation, the conducted iterative ADR approach starts with building the first artifact's design, which is shaped by the intervention of the organizations and subsequent evaluation [25]. Following [Principle 4: Mutually Influential Roles], the researchers and the practitioners contributed theoretical and practical knowledge, respectively. This knowledge base was enriched by the case projects' consultancy teams and industry partners, who adopted the typical end-user role in the ADR cycles. These contributions were mutually intertwined [Principle 3: Reciprocal Shaping]. Besides, the researcher team has a practical background in IT consulting and business process management. Since we aim for DPs informing an IT-artifact that supports companies in the context of their DT, we focus on an organization-dominant Building, Intervention, and Evaluation approach mainly based on organizational interventions [25]. In parallel, an ongoing design-accompanied evaluation [60] with the industry partners and consultancy teams took place [Principle 5: Authentic and Concurrent Evaluation].

Meeting and workshop protocols, observations, and interviews with the industry partners of "Future Retail", "Smart Container", and "Future Bike" informed the first set of DPs (cf. Section IV). The interviews followed the guidelines for semi-structured interviews by Myers and Newman [61]. The researcher team internally discussed the findings from the case projects and iteratively revised the DPs. For instance, the assessment and selection of ideas were raised as an important issue in the orientation phase. Thus, idea management became a relevant domain and was included in the set of DPs. The feedback of the industry partners and the internal discussions shaped the formulation of further guiding questions for later interventions (cf. [54], [61]). Furthermore, the practical find- ings were validated based on the above-mentioned hermeneutic literature review. A focus group discussion was conducted to assess the first set of DPs [62]. In the next sub-section, the setup of the focus group discussion is explained in detail. Based on this feedback, the set of DPs was then refined (cf. Section V within internal discussions in the researcher team. Subsequently, we implemented a software prototype based on the list of DPs (cf. Section VI). The trajectory of the Building, Intervention, and Evaluation stage is depicted in Figure 2.

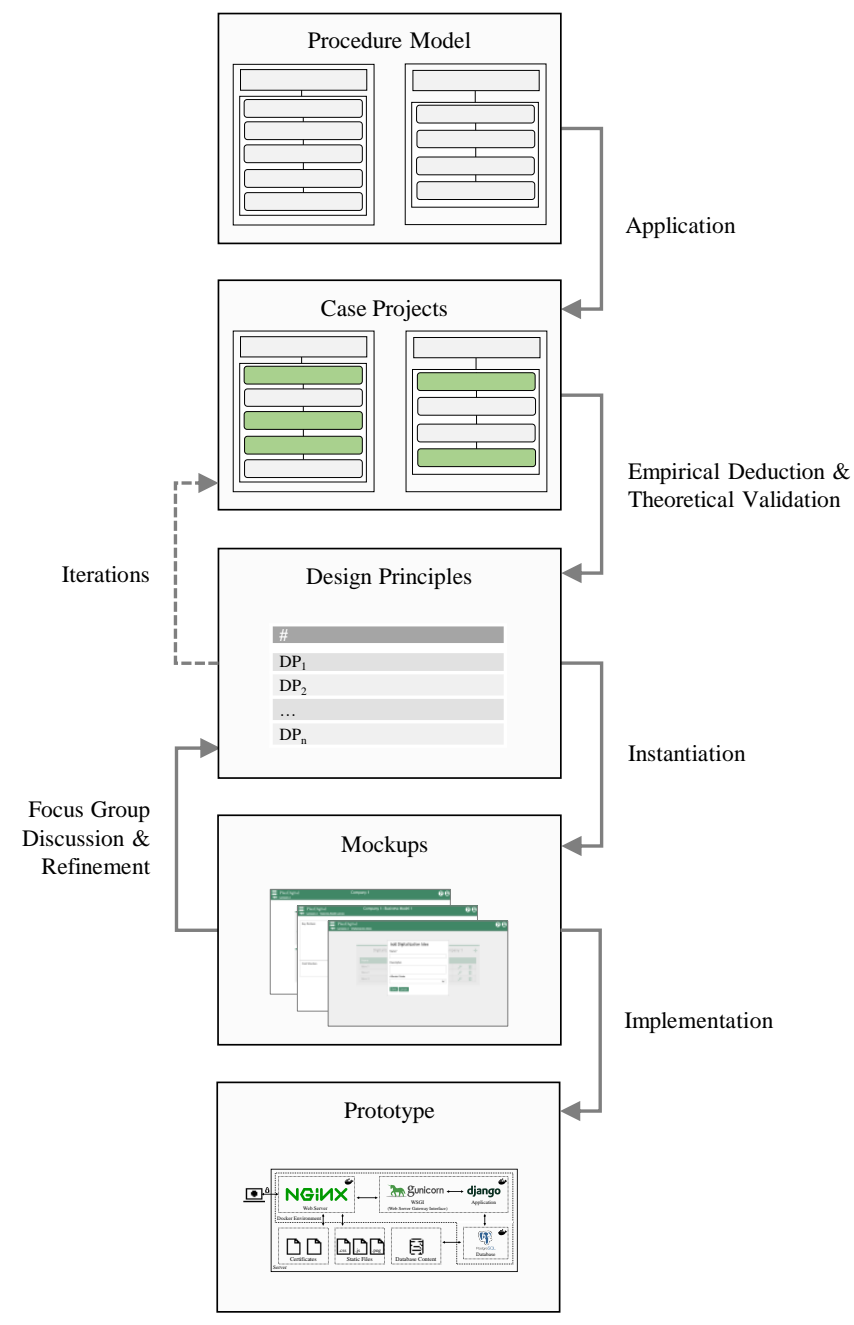

Fig. 2. Trajectory of the Building, Intervention, and Evaluation stage.

The Reflection and Learning stage has accompanied the performed case projects. Through the feedback provided by the 
practitioners and end-users, the list of DPs was continuously reviewed and enhanced by integrating what is relevant in contemporary practice. This stage led to substantial changes in the design of the IT-artifact based on ongoing evaluations and reflections conducted with the case project's consultancy teams and industry partners [Principle 6: Guided Emergence]. In addition, by combining empirical findings, theoretical validation, and the iterative self-verifying nature of the Building, Intervention, and Evaluation cycles, the design process is multi-grounded (cf. [63]).

In the Formalization of Learning stage, to prove the artifact's generalizability, we conducted a focus group discussion as an evaluation step involving practitioners and end-users [Principle 7: Generalized Outcome]. The integration of endusers increases the reliability of the evaluation. Furthermore, with this research paper, we formalize the research outcome and disseminate it.

\section{B. Focus Group Discussion}

A focus group discussion is a qualitative research method with a focus on group interaction [64], [65]. This method can be used for artifact evaluation and refinement [66] and proved useful for the intervention within ADR cycles (cf. [25]).

We followed the focus group steps proposed by Tremblay et al. [66]. The goal of the focus group was to assess the DPs and to derive possible improvements. To make the DPs accessible for the participants, we translated the DPs into mockups visualizing the intended software tool. For the discussion, a group of four participants (two practitioners, two end-users) was chosen. None of them was involved in the development of the DPs before the focus group discussion. The practitioners and end-users have intermediate to comprehensive experiences with digitalization projects. More specifically, the end-users were involved in the first case project "Future Retail" as juniorlevel project staff, and the practitioners are employees of a local startup accelerator hub who also worked in digitalization projects from different industries for several years.

The researcher team presented a set of mockups via screen sharing and explained the essential features. The discussion was supported by a prepared script, including a list of guiding questions. The participants had the option to see selected mockups via screen sharing and discuss the screens and their planned features. If necessary, one researcher actively guided the discussion and asked questions such as "What would you add/leave out in the tool?" and "When would you use the tool?". The transcribed recording served as the basis for subsequent discussions and potential adjustments.

\section{DESIGN PRINCIPLES}

The findings of the case projects were discussed in order to derive the first set of DPs for the software tool, which are summarized in Table [I] The indicated scientific sources confirm the practical findings and provide a theoretical validation. To structure the collection of DPs, we adopted the three meta-dimensions of the taxonomy for business model development tool functions by Szopinski et al. [15]: Modeling,
Collaboration, and Technical. In addition, General design describes general design choices. Such meta-requirements have proven useful to structure the design of artifacts like the proposed set of DPs [53], [67], [68]. Since the intended tool is supposed to support the orientation phase of a company's DT, the design mirrors selected concepts of the procedure model by Barann et al. [7], e.g., company goal, business model, and digitalization roadmap, to which we refer when introducing the DPs. Moreover, we separate digital practices and digital technologies, with which digital practices can be realized, as different technology layers (cf. Sections II-A \& II-B])

General design: The case projects have proven that it is purposeful to discuss possible alternative digital practices and digital technologies during the orientation phase to provide practical orientation (DPG1) [7], [21], [22]. To enable a more convenient implementation and usage, available concepts and features from existing tools should be reused if applicable (DPG2) [40]. Due to its dissemination and acceptance in practice, we stick to the business model framework by Osterwalder and Pigneur [73] as the basic structure for modeling a company's business model. For the design of the roadmap, a simplified single-layered technology roadmap with different timeframes (cf. [46]) was considered appropriate to organize digitalization ideas (DPG2). Furthermore, we identified the need to enable the integration of external supporters into the tool's workflow. More specifically, there is evidence that the integration of external ideators or expert reviewers such as digitalization coaches is of great benefit in the context of the activities identifying, evaluating, and selecting ideas (DPG3) [7], [22], [51], [69]. The precondition of this principle is the tool's general capability to support these activities, which essentially describe the various phases of idea management (DPG4) [11], [21], [22], [40]. The case projects have shown that it is useful to begin workshops from different starting points, e.g., from the business model, company goal, or digitalization roadmap perspective (DPG5) [7].

Modeling: The tool should allow adding elements (e.g., newsletter) to business model components (e.g., customer channels) to depict the company's business model [52]. On an individual digitalization roadmap (DPM2) [7], [46], the user should be able to arrange digitalization ideas along a timeline with distinct timeframes (DPG1 \& DPM3) [7], [21], [40] and connect them to specific company goals (DPM1) [7], [24], [40]. The documentation of company goals could be facilitated via a corresponding input form. In addition, all levels of digital innovation shall be supported. In other words, the software tool requires features that support both small-scale process improvements and more radical changes targeting the entire business logic (DPM5) [51], [72]. This could be achieved through clear and easy-to-understand links between, e.g., digitalization ideas and affected business model components or company goals (DPM6) [51], [72]. Such links could be explicitly highlighted by, e.g., hover events or colors. To support the generation of digitalization ideas, the tool should allow linking these with existing digital technologies (DPM4 \& DPM6) [51], [72]. The tool should enable the user to 
TABLE II

DESIGN PRINCIPLES (DPS) DERIVED FROM THE CASE PROJECTS.

\begin{tabular}{|c|c|c|}
\hline ID & Short description & Theoretical validation \\
\hline \multicolumn{3}{|c|}{ General design } \\
\hline DPG1 & Provision of practical orientation. & [7], [21], [22] \\
\hline DPG2 & Reuse of common, disseminated, and comprehensible tools. & [40] \\
\hline DPG3 & Integration of external supporters. & [7], [11], [22], [51], [69] \\
\hline DPG4 & Support all phases of idea management. & [11], |21], |22], |40] \\
\hline DPG5 & No predefined path through the application has to be followed. & [7] \\
\hline \multicolumn{3}{|c|}{ Modeling } \\
\hline DPM1 & Consideration of tangible company goals. & [7], [24], [40], [70] \\
\hline DPM2 & Provision of an individual roadmap. & [7], [46], [70] \\
\hline DPM3 & Enabling a step-wise implementation. & [7], [21], [40] \\
\hline DPM4 & Identification of possible solution alternatives. & [7], [24] \\
\hline DPM5 & Support all levels of digital innovation. & [7], [21], [71] \\
\hline DPM6 & Links between tool components are easy to grasp. & [51], 172$]$ \\
\hline DPM7 & Content can be edited in a simple manner. & {$[51],[72]$} \\
\hline \multicolumn{3}{|c|}{ Collaboration } \\
\hline DPC1 & Projects are strictly separated and accessible by assigned users. & [22], 172 \\
\hline DPC2 & Content can be modeled by multiple users asynchronously. & [22], [40], 172] \\
\hline \multicolumn{3}{|c|}{ Technical } \\
\hline DPT1 & The tool can be readily accessed without installation efforts. & [21], 72 \\
\hline DPT2 & Results can be exported as a summarizing protocol. & {$[72]$} \\
\hline
\end{tabular}

edit content like business model (components), digitalization ideas, digital technologies, and company goals (DPM7) [51], [72]. Digitalization ideas should have an assessment feature to make them comparable (DPG4 \& DPM7) [51].

Collaboration: A basic user and role management (i.e., authorization concept) is needed to separate the projects and ensure data protection and security (DPC1) [22], [72]. Furthermore, multiple users should be able to asynchronously model content, e.g., digitalization ideas on the digitalization roadmap (DPC2) [22], [40], [72]. As the tool is expected to be used in a (virtual) face-to-face setting rather than concurrently by different users, communication, version control, and conflict management features [51], [52], [72] are deemed less relevant for the initial design.

Technical: The intended software tool should be implemented as a web application to make it more accessible when it is used ad hoc in workshops (DPT1) [21], [72]. An export function needs to be implemented to be able to generate a protocol for the workshop participants (DPT2) [72]. In this context, it has been proven meaningful to present the digitalization roadmap as the result of a corresponding workshop.

\section{Evaluation \& Refinement}

In a focus group discussion, the previously defined DPs have been evaluated (cf. Section III-B). To make them accessible for the participants, we translated the DPs into mockups to visualize the intended software features (cf. Figure 3). Overall, the participants confirmed the usefulness and usability of the intended software tool. Notably, the interdependencies between digitalization ideas on a roadmap help practitioners to better grasp their relevance for a company's DT. The participants highlighted the importance of simple assessment features of the digitalization ideas to make them comparable, even though these assessments are rather based on gut feeling than on proper key performance indicators. One participant emphasized the relevance of the integrated annotation feature to enrich digitalization ideas. Also, the documentation of digitalization ideas on a roadmap helps to determine progress in the sense of the DT's impact on the company.

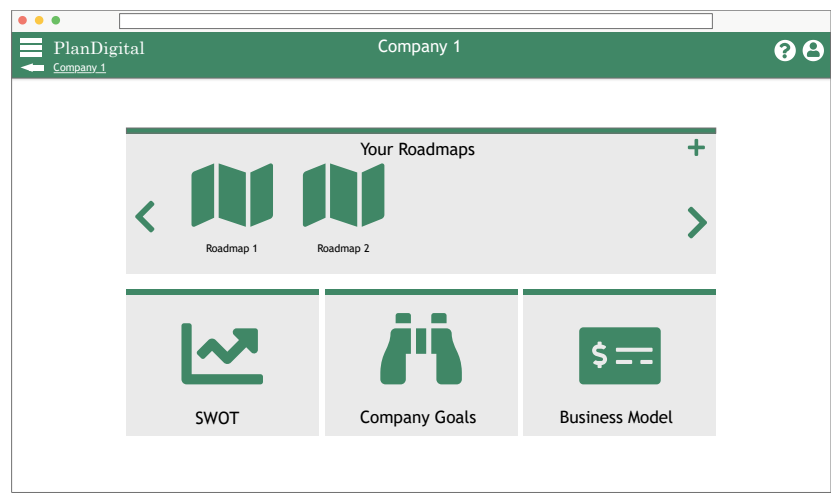

Fig. 3. Exemplary mockup of the start screen [74].

Besides these generally positive perceptions, the participants criticized specific design decisions. To increase the ease-ofuse, one practitioner suggested making the tool configurable, e.g., by hiding individual screens and features from the enduser if these are not necessary for a particular workshop. One end-user proposed an "ideation space" to collect digitalization ideas before they are being mapped onto the roadmap timeline.

Based on the insights from the focus group discussion and changing circumstances due to the COVID-19 pandemic 
(explained in the following), some design decisions had to be reviewed and revised as follows. The resulting changes are introduced as new or revised DPs, which complement the first set of DPs (cf. Table III).

The researcher team agreed to follow the suggestion of making the tool's interface and features personalizable. Hence, DPG5 was refined accordingly [7]. The usefulness of the proposed "ideation space" has been acknowledged by the researcher team as well. This feature should enable the user to create digitalization ideas without any relation to a particular roadmap (DPM8) [21], [22], [24], [40], [51]. Also, as the first case project (i.e., "Future Retail") was completed prior to the COVID-19 pandemic, the software tool was initially designed to support face-to-face settings (e.g., on-site workshops). During the pandemic, virtual meetings and decentralized work have become more important (cf. [75], [76]). Thus, more advanced collaboration features can facilitate using the central features in a virtual environment. In its current design, most of the tool's features can be used in virtual meetings via screen sharing. However, a repository and conflict management is required when multiple users work concurrently in the same modeling environment (DPC3) [22], [72].

\section{TOOL PROTOTYPE}

Based on the formulated DPs, we designed a set of clickable mockup $\mathrm{s}^{1}$ and developed a prototype of the intended software tool using the Python web framework Django (cf. Figure 4). The prototype implements the first set of DPs (cf. Section IV) as well as DPM8 (cf. Section V). For instance, DPM8 was implemented by allowing the generation of ideas independent from their immediate evaluation or positioning on the roadmap. The revised DPG5, DPC3, and further improvement potentials, which might emerge during the tool's real-world application, will be later integrated in a modular manner. Therefore, we consider the implemented software tool as a living artifact, which can result in additional DPs that would be added to the current list of DPs. Likewise, the list of DPs is a living artifact in the sense of possible extensions, but not in the sense of changes to the current DPs. The following elaborations highlight the core features of the software tool and are, hence, not exhaustive.

At the center of the prototype is the company-specific set of digitalization roadmaps, each structuring digitalization ideas regarding a particular subject area. For instance, a company might want to define two roadmaps, one for ideas related to customer communication and one for internal process optimization. A roadmap structures ideas in terms of shortterm, mid-term, long-term, and as-is, and thereby serves as a company-specific DT agenda that can continuously be updated. Every idea on a roadmap can be explicitly linked to the company's goals and business model, which can both be defined and updated in a dedicated view. Thereby, the tool intertwines the management of digitalization ideas with important DT perspectives, i.e., the current business model

${ }^{1}$ https://www.voil.eu/en/PlanDigital and strategy. Ideas on a roadmap can be evaluated regarding selected idea evaluation criteria such as implementation effort or expected costs. The individual evaluations, in combination with the expected effects to company goal fulfillment and the business model, provide the basis for a subsequent idea selection and arrangement on a roadmap.

The tool is intended to be applied in face-to-face workshop settings. The envisioned settings bring together the management of companies and DT professionals (e.g., external consultants). From an implementation perspective, the tool integrates a separate role for digitalization coaches (e.g., external or internal ideators). Moreover, the software tool is deployed as a web application to make it readily accessible without additional setup efforts. The application implements a standard authentication and authorization concept to restrict the tool's features to eligible users only.

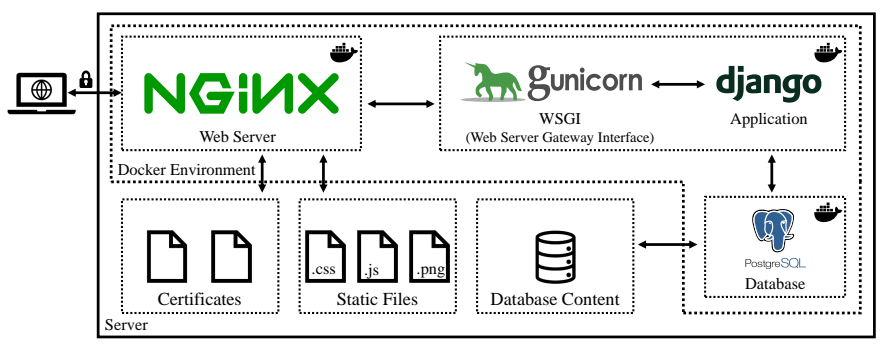

Fig. 4. Technology stack of the tool prototype [74].

\section{DISCUSSION}

In the following, we formalize generalized learnings as a result of the applied ADR approach. In accordance with Schwarz and Legner [16], we understand the resulting ITartifact as a business model tool addressing all three perspectives: method, (conceptual) model, and IT-support [16]. Therefore, the IT-artifact can be discussed as a boundary object, which enables and fosters (strategic) conversations between various actors [16], [51], [77]. Also, our research confirms technology roadmap-related features as meaningful extensions to business model development tools as they can compensate for the missing interrelationship over time, i.e., dynamics. Corresponding tools often miss the opportunity to implement features for visualizing those dynamics [15]. However, dynamics regarding the technology perspective are particularly relevant for DT. Further research can review features of business model tools and propose artifacts with respect to other identified criteria of dynamics in business model frameworks (cf. [20]).

Moreover, our research demonstrates how technology can be discussed on different layers (cf. Section II-A) in order to facilitate DT. We were able to separate digital technologies (i.e., component) from technology-enabled digital practices (i.e., approach) and arrange them in the form of possible digitalization ideas onto topic-related digitalization roadmaps (i.e., concept) [35]. Hence, we argue that discussing (digital) technology on different layers by separating concept, 
TABLE III

DESIGN PRINCIPLES (DPS) DERIVED FROM THE FOCUS GROUP DISCUSSION.

\begin{tabular}{|c|c|c|}
\hline ID & Short description & Theoretical validation \\
\hline \multicolumn{3}{|c|}{ General design } \\
\hline DPG5* & Provide a personalizable user interface, usage path, and feature set. & 7] \\
\hline \multicolumn{3}{|c|}{ Modeling } \\
\hline DPM8 & The tool supports a step-wise ideation process. & $21,22], 24], 40], 51$ \\
\hline \multicolumn{3}{|c|}{ Collaboration } \\
\hline DPC3 & Content can be modeled by multiple users synchronously. & 22], 72$]$ \\
\hline
\end{tabular}

approach, and component enables a more straightforward discourse about possible digitalization initiatives, especially in the early orientation phase of a company's DT.

Furthermore, we emphasize the relevance of integrated idea management (i.e., identifying, evaluating, and selecting ideas) to prepare a company's DT in a structured way. For instance, we integrate essential idea management principles such as the ability to persist ideas in an idea database or collaborative ideation and enhance them by DT-relevant specifics [74]. So far, idea management has been studied traditionally in a much broader context, namely, product innovation (cf. [78]). Therefore, we extend the research area of idea management by integrating research about DT and vice versa. More specifically, the tool is a unique re-combination of different (conceptual) models from both research areas. Moreover, the tool can be seen as an instantiation of certain phases from respective procedure models proposed in both research areas [74]. Besides, the amount and diversity of data gained through the potential dissemination and application of the tool motivate and inform future research with respect to these research areas. For instance, the collected data may help reveal technology trends or determine the digital maturity of certain industries [74].

Although we did not explicitly follow a specific formulation guideline (cf. [79], [80]), the DPs can be considered actionand materiality-oriented, according to Chandra et al. [27]. The set of DPs ultimately sheds light on how to design supporting software tools in the context of DT. These DPs not only shape the implementation of the presented software tool (cf. Section VI). Due to their abstract nature, they can generally inform tools supporting the orientation phase of a company's DT. For instance, DPG2 is not limited to the utilization of the business model framework by Osterwalder and Pigneur [73] or the technology roadmap design by Schaller et al. [46]. Other tools might reuse other existing concepts and features fitting their concrete purpose.

During the research process, adjustments were made to the ADR approach. In the early ADR cycles, the practitioner role was solely represented by the researchers' double role. In particular, within the internal discussions, the individual researchers switched roles (researcher and practitioner) due to their practical experience as former IT consultants. Therefore, the results of the early cycles might be biased. To fully comply with the ADR principles by Sein et al. [25], for the focus group discussion, two employees of a local startup accelerator hub have been invited as practitioners to discuss the tool design.

Finally, the following two matters need to be stressed as limitations. First, the choice to base the tool design on the general logic of the procedure model by Barann et al. [7] needs to be revisited. The tool is intended to be applicable in organizations regardless of their size, while the procedure model by Barann et al. [7] does indeed focus on supporting SMEs. Consequently, the tool might be more relevant in an SME context, either. At the same time, the model's focus needs to be taken with caution. The SME-specific nature of the model is established by integrating the supporting role of (external) digital innovation units along with the procedure, which, however, does not change the steps and their procedural order.

Second, the set of DPs was empirically derived in the context of only three case projects which was, therefore, additionally theoretically validated with scientific sources (cf. Section III-A). Despite the meaningful insights derived from the case projects, the focus group discussion, and the hermeneutic literature review, additional use cases might have contributed to the robustness of the DPs. Yet, the evaluation of the tool design is formative, artificial (cf. [81]). However, a summative, naturalistic evaluation of the tool design may be beneficial to get reasonable evaluation insights when the implemented tool is applied in real-world scenarios with different company types (e.g., size, industry, digital maturity). More features might be included as we consider the list of DPs and the software tool as living artifacts. This motivates future research regarding the evaluation and feasible extensions of the software tool.

\section{CONCLUSION}

In rapidly changing environments induced by the emergence of new technologies along with a number of technologyenabled digital practices, companies easily lose track of possible digitalization ideas that are relevant for their business. Although practice and academia created dedicated methods for ideation-support in the context of DT, little attention has been paid to support the ideation and documentation of companyspecific digitalization ideas in an integrated fashion.

Addressing this issue and answering the stated research question, this paper proposes the design of a tool that combines essential concepts of idea management and DT to support companies in their DT endeavors. The tool allows the user to 
compile company-specific roadmaps presenting a collection of digitalization ideas augmented by additional information, e.g., about relevant technologies or interdependencies with respect to the current business model.

Applying the tool in practice may fulfill multiple purposes for companies. First, the documentation of digitalization roadmaps may serve as a personalized agenda for a company's DT. Second, this agenda may be used as a practitioner-friendly means for communication. Third, the tool may be employed for documenting and structuring digitalization ideas to provide overview and guidance in a rapidly progressing DT [74].

The design ultimately addresses the gap between theoretical work on DT (such as DT procedures, DT strategies, etc.) and practitioners' needs. The perceived simplicity and relevance of existing business model tools were transferred to the concept of technology roadmaps and integrated into a bundled software design. From a theoretical perspective, we conceptualized the design and structured the development process of IT-artifacts for supporting the orientation phase of a company's DT.

\section{ACKNOWLEDGMENTS}

This work was created in the context of a project that received funding from the Bundesministerium für Wirtschaft und Energie (BMWi) under the grant agreement 01MF17011D.

\section{REFERENCES}

[1] M. Graf, M. Peter, and S. Gatziu-Grivas, "Foster Strategic Orientation in the Digital age: A Methodic Approach for Guiding SME to a Digital Transformation," in Bus. Inf. Syst. Work. Abramowicz, Witold; Paschke, Adrian, 2019, vol. 339, pp. 420-432.

[2] J. Reis, M. Amorim, N. Melao, and P. Matos, "Digital Transformation: A Literature Review and Guidelines for Future Research," in WorldCIST 2018 Trends Adv. Inf. Syst. Technol., A. Rocha, H. Adeli, L. Reis, and S. E. Costanzo, Eds. Springer, Cham, 2018, pp. 411-421.

[3] I. M. Sebastian, K. G. Moloney, J. W. Ross, N. O. Fonstad, C. Beath, and M. Mocker, "How big old Companies Navigate Digital Transformation," MIS Q. Exec., vol. 16, no. 3, pp. 197-213, 2017.

[4] H. Chesbrough, "Business Model Innovation: Opportunities and Barriers," Long Range Plann., vol. 43, no. 2-3, pp. 354-363, apr 2010.

[5] C. Zott, R. Amit, and L. Massa, "The Business Model: Recent Developments and Future Research," J. Manage., vol. 37, no. 4, pp. 1019-1042, 2011.

[6] C. Kerr, L. Mortara, R. Phaal, and D. Probert, "A Conceptual Model for Technology Intelligence," Int. J. Technol. Intell. Plan., vol. 2, no. 1, pp. 73-93, 2006.

[7] B. Barann, A. Hermann, A.-K. Cordes, F. Chasin, and J. Becker, "Supporting Digital Transformation in Small and Medium-sized Enterprises: A Procedure Model Involving Publicly Funded Support Units," in Proc. 52nd Hawaii Int. Conf. Syst. Sci., Wailea, Hawaii, 2019, pp. 4977-4986.

[8] B. W. Wirtz and M.-J. Thomas, "Design und Entwicklung der Business Model-Innovation," in Kompend. Geschäftsmodell-Innovation. Wiesbaden: Springer Fachmedien Wiesbaden, 2014, pp. 31-49.

[9] C. Zott and R. Amit, "Business Model Innovation: Towards a Process Perspective," in Oxford Handb. Creat. Innov. Entrep., C. Shalley, M. A. Hitt, and J. Zhou, Eds. New York: Oxford University Press, 2015, pp. 395-406.

[10] A. Heberle, W. Lowe, A. Gustafsson, and O. Vorrei, "Digitalization Canvas-Towards Identifying Digitalization Use Cases and Projects." $J$. Univers. Comput. Sci., vol. 23, no. 11, pp. 1070-1097, 2017.

[11] A. Brem and K.-I. Voigt, "Innovation Management in Emerging Technology Ventures - The Concept of an Integrated Idea Management," Int. J. Technol. Policy Manag., vol. 7, no. 3, pp. 304-321, 2007.

[12] M. Stevanovic, D. Marjanović, and M. Štorga, "A Model of Idea Evaluation and Selection for Product Innovation," in Proc. 20th Int. Conf. Eng. Des. (ICED 15), 2015, pp. 193-202.
[13] C. Pelletier and L. M. Cloutier, "Conceptualising digital transformation in SMEs: an ecosystemic perspective," J. Small Bus. Enterp. Dev. vol. 26, no. 6-7, pp. 855-876, dec 2019.

[14] M. Fruhwirth, C. Ropposch, and V. Pammer-Schindler, "Supporting Data-Driven Business Model Innovations - A structured Literature Review on Tools and Methods Michael," J. Bus. Model., vol. 8, no. 1, 2020.

[15] D. Szopinski, T. Schoormann, T. John, R. Knackstedt, and D. Kundisch, "Software Tools for Business Model Innovation: Current State and Future Challenges," Electron. Mark., vol. 30, no. 3, pp. 469-494, sep 2020.

[16] J. S. Schwarz and C. Legner, "Business Model Tools at the Boundary: Exploring Communities of Practice and Knowledge Boundaries in Business Model Innovation," Electron. Mark., vol. 30, no. 3, pp. 421445, aug 2020.

[17] G. Vial, "Understanding Digital Transformation: A Review and a Research Agenda," J. Strateg. Inf. Syst., vol. 28, no. 2, pp. 118-144, jun 2019.

[18] L. Wessel, A. Baiyere, R. Ologeanu-Taddei, J. Cha, and T. Blegind Jensen, "Unpacking the Difference Between Digital Transformation and IT-Enabled Organizational Transformation," J. Assoc. Inf. Syst., vol. 22, no. 1 , pp. $102-129$, jan 2021.

[19] Z. van Veldhoven and J. Vanthienen, "Digital Transformation as an Interaction-driven Perspective Between Business, Society, and Technology," Electron. Mark., mar 2021.

[20] H. Khodaei and R. Ortt, "Capturing Dynamics in Business Model Frameworks," J. Open Innov. Technol. Mark. Complex., vol. 5, no. 1, p. 8, 2019.

[21] C. Sandström and J. Björk, "Idea Management Systems for a Changing Innovation Landscape," Int. J. Prod. Dev., vol. 11, no. 3-4, pp. 310-324, 2010.

[22] S. Gerlach and A. Brem, "Idea Management Revisited: A Review of the Literature and Guide for Implementation," Int. J. Innov. Stud., vol. 1, no. 2, pp. 144-161, nov 2017.

[23] S. Wagner, P. M. Bican, and A. Brem, "Critical Success Factors in the Front End of Innovation: Results From an Empirical Study," Int. J. Innov. Manag., vol. 25, no. 04, pp. 1-36, may 2021.

[24] M. Stevanović, D. Marjanović, and M. Storga, "Decision Support System for Idea Selection," in Int. Des. Conf., Dubrovnik, Croatia, 2012, pp. $1951-1960$

[25] Sein, Henfridsson, Purao, Rossi, and Lindgren, "Action Design Research," MIS Q., vol. 35, no. 1, pp. 37-56, 2011.

[26] J. Iivari, "Towards Information Systems as a Science of Meta-Artifacts," Commun. Assoc. Inf. Syst., vol. 12, no. 1, pp. 568-581, 2003.

[27] L. Chandra, S. Seidel, and S. Gregor, "Prescriptive Knowledge in IS Research: Conceptualizing Design Principles in Terms of Materiality, Action, and Boundary Conditions," in Proc. 48th Hawaii Int. Conf. Syst. Sci., vol. 2015-March. Kauai, HI, United States: IEEE, 2015, pp. 40394048.

[28] A. R. Hevner, "A Three Cycle View of Design Science Research," Scand. J. Inf. Syst., vol. 19, no. 2, pp. 87-92, 2007.

[29] S. Gregor and A. R. Hevner, "Positioning and Presenting Design Science Research for Maximum Impact," MIS Q., vol. 37, no. 2, pp. 337-355, 2013.

[30] C. Matt, T. Hess, and A. Benlian, "Digital Transformation Strategies," Bus. Inf. Syst. Eng., vol. 57, no. 5, pp. 339-343, 2015.

[31] S. Berghaus and A. Back, "Stages in Digital Business Transformation: Results of an Empirical Maturity Study," in MCIS 2016 - 10th Mediterr. Conf. Inf. Syst., Paphos, Cyprus, 2016, pp. 1-17.

[32] F. Wiesböck and T. Hess, "Digital Innovations: Embedding in Organizations," Electron. Mark., vol. 30, no. 1, pp. 75-86, 2020.

[33] B. Vandenbosch, A. Saatcioglu, and S. Fay, "Idea Management: A Systemic View*," J. Manag. Stud., vol. 43, no. 2, pp. 259-288, 2006.

[34] E. M. Rogers, Diffusion of Innovations, 4th ed. New York, USA: Simon and Schuster, 2010.

[35] S. Berger, M. S. Denner, and M. Röglinger, "The Nature of Digital Technologies - Development of a Multi-Layer Taxonomy," in ECIS 2018 - 26th Eur. Conf. Inf. Syst., Portsmouth, UK, 2018, pp. 1-18.

[36] S. T. March and G. F. Smith, "Design and Natural Science Research on Information Technology," Decis. Support Syst., vol. 15, no. 4, pp. 251-266, 1995

[37] P. M. Leonardi, "When Flexible Routines Meet Flexible Technologies: Affordance, Constraint, and the Imbrication of Human and Material Agencies," MIS Q., vol. 35, no. 1, pp. 147-167, 2011. 
[38] A. Osterwalder, "The Business Model Ontology - A Proposition in a Design Science Approach,” Ph.D. dissertation, University of Lausanne, 2004.

[39] N. J. Foss and T. Saebi, "Fifteen Years of Research on Business Model Innovation: How Far Have we Come, and Where Should we Go?" J. Manage., vol. 43, no. 1, pp. 200-227, 2016.

[40] M. D. L. Flynn, D. O’Sullivan, and K. Cormican, "Idea Management for Organisational Innovation,” Int. J. Innov. Manag., vol. 7, no. 4, pp. 417-442, dec 2003.

[41] J. Gray and B. Rumpe, "Models for the Digital Transformation," Softw. Syst. Model., vol. 16, no. 2, pp. 307-308, may 2017.

[42] K. C. Desouza, C. Dombrowski, Y. Awazu, P. Baloh, S. Papagari, S. Jha, and J. Y. Kim, "Crafting Organizational Innovation Processes," Innov. Organ. Manag., vol. 11, no. 1, pp. 6-33, 2009.

[43] S. J. Berman, "Digital Transformation: Opportunities to Create new Business Models," Strateg. Leadersh., vol. 40, no. 2, pp. 16-24, 2012.

[44] M. de Reuver, H. Bouwman, and T. Haaker, "Business Model Roadmapping: A practical Approach to come from an Existing to a Desired Business Model," Int. J. Innov. Manag., vol. 17, no. 1, pp. 1-18, 2013.

[45] M. A. Toro-Jarrín, I. E. Ponce-Jaramillo, and D. Güemes-Castorena, "Methodology for the of Building Process Integration of Business Model Canvas and Technological Roadmap," Technol. Forecast. Soc. Change, vol. 110, pp. 213-225, 2016.

[46] A. A. Schaller, R. Vatananan-Thesenvitz, and M. Stefania, "Business Model Innovation Roadmapping: A Structured Approach to a new Business Model," in PICMET 2018 - Portl. Int. Conf. Manag. Eng. Technol. Manag. Technol. Entrep. Engine Econ. Growth, Honolulu, HI, 2018.

[47] R. Phaal, C. J. P. Farrukh, and D. R. Probert, "Technology Roadmapping - A Planning Framework for Evolution and Revolution," Technol. Forecast. Soc. Change, vol. 71, no. 1-2, pp. 5-26, 2004.

[48] European Industrial Research Management Association, "Technology Roadmapping: Delivering Business Vision,” in Work. Gr. Rep. EIRMA, 1997, vol. 52.

[49] B. Farrokhzad, C. Kern, and M. de Vries, "Innovation Business Plan at Siemens: Portfolio-based Roadmapping to Convert Promising Innovation Projects into Concrete Successes," Int. J. Technol. Intell. Plan., vol. 4, no. 2, pp. 153-164, 2008.

[50] K. Täuscher and N. Abdelkafi, "Visual Tools for Business Model Innovation: Recommendations From a Cognitive Perspective," Creat. Innov. Manag., vol. 26, no. 2, pp. 160-174, 2017.

[51] P. Ebel, U. Bretschneider, and J. M. Leimeister, "Leveraging Virtual Business Model Innovation: A Framework for Designing Business Model Development Tools," Inf. Syst. J., vol. 26, no. 5, pp. 519-550, 2016.

[52] D. Szopinski, T. Schoormann, T. John, R. Knackstedt, and D. Kundisch, "How software can Support Innovating Business Models: A Taxonomy of Functions of Business Model Development Tools," in AMCIS 2017 23rd Am. Conf. Inf. Syst. A Tradit. Innov., Boston, MA, 2017.

[53] F. Möller, T. M. Guggenberger, and B. Otto, "Towards a Method for Design Principle Development in Information Systems," in DESRIST 2020 - 15th Int. Conf. Des. Sci. Res. Inf. Syst. Technol., Kristiansand, Norway, 2020, pp. 208-220.

[54] B. Kühne and T. Böhmann, "Data-Driven Business Models - Building the Bridge Between Data and Value," in ECIS 2019 - 27th Eur. Conf. Inf. Syst., Stockholm \& Uppsala, Sweden, 2019, pp. 1-16.

[55] A. Haj-Bolouri and M. Rossi, "Towards Design Principles for Safety Training in Virtual Reality: An Action Design Research Case," in DESRIST 2021 - 16th Int. Conf. Des. Sci. Res. Inf. Syst. Technol., Kristiansand, Norway, 2021, pp. 89-95.

[56] M. Mandviwalla and R. Flanagan, "Small Business Digital Transformation in the Context of the Pandemic," Eur. J. Inf. Syst., vol. 30, no. 4, pp. 359-375, jul 2021.

[57] P. Barthel, C. Fuchs, B. Birner, and T. Hess, "Embedding Digital Innovations in Organizations: A Typology for Digital Innovation Units," in Proc. 15th Int. Conf. Wirtschaftsinformatik, mar 2020, pp. 780-795.

[58] R. Kohli and N. P. Melville, "Digital Innovation: A Review and Synthesis," Inf. Syst. J., vol. 29, no. 1, pp. 200-223, jan 2019.

[59] S. K. Boell and D. Cecez-Kecmanovic, "A Hermeneutic Approach for Conducting Literature Reviews and Literature Searches," Commun. Assoc. Inf. Syst., vol. 34, no. 1, pp. 257-286, 2014.

[60] J. Becker, P. Delfmann, R. Knackstedt, and D. Kuropka, "Konfigurative Referenzmodellierung," in Wissensmanagement mit Ref. Springer, 2002, pp. 25-144.
[61] M. D. Myers and M. Newman, "The Qualitative Interview in IS Research: Examining the Craft," Inf. Organ., vol. 17, no. 1, pp. 2-26, 2007.

[62] T. Ochieng Nyumba, K. Wilson, C. J. Derrick, and N. Mukherjee, "The use of Focus Group Discussion Methodology: Insights From two Decades of Application in Conservation," Methods Ecol. Evol., vol. 9, no. 1 , pp. 20-32, 2018

[63] G. Goldkuhl, "Design Theories in Information Systems-a Need for Multi-Grounding," J. Inf. Technol. Theory Appl., vol. 6, no. 2, pp. 59-72, 2004.

[64] J. Kitzinger, "Qualitative Research: Introducing Focus Groups," BMJ, vol. 311, pp. 299-302, 1995.

[65] D. Morgan, "Planning and Research Design for Focus Groups," in Focus Groups as Qual. Res., 2nd ed. 2455 Teller Road, Thousand Oaks California 91320 United States of America: SAGE Publications, Inc., 1997, pp. 31-45.

[66] M. C. Tremblay, A. R. Hevner, and D. J. Berndt, "Focus Groups for Artifact Refinement and Evaluation in Design Research," Commun. Assoc. Inf. Syst., vol. 26, 2010.

[67] J. G. Walls, G. R. Widmeyer, and O. A. El Sawy, "Building an Information System Design Theory for Vigilant EIS," Inf. Syst. Res., vol. 3, no. 1, pp. 36-59, mar 1992.

[68] F. Möller, H. Haße, C. Azkan, H. van der Valk, and B. Otto, "Design of Goal-Oriented Artifacts from Morphological Taxonomies: Progression from Descriptive to Prescriptive Design Knowledge," in Proc. 16th Int. Conf. Wirtschaftsinformatik, Essen, Germany, 2021.

[69] N. Thom, "Idea Management in Switzerland and Germany: Past, Present and Future," Die Unternehmung, vol. 69, no. 3, pp. 238-254, 2015.

[70] V. Stich, V. Zeller, J. Hicking, and A. Kraut, "Measures for a Successful Digital Transformation of SMEs," in Procedia CIRP, vol. 93. Elsevier B.V., 2020, pp. 286-291.

[71] M. P. Rice, G. C. O'Connor, L. S. Peters, and J. G. Morone, "Managing Discontinuous Innovation," Res. Technol. Manag., vol. 41, no. 3, pp. 52-58, 1998.

[72] K. Riemer, J. Holler, and M. Indulska, "Collaborative Process Modelling-tool Analysis and Design Implications," in Proc. 19th Eur. Conf. Inf. Syst. (ECIS 2011), Helsinki, Finland, 2011.

[73] A. Osterwalder and Y. Pigneur, Business Model Generation: A Handbook for Visionaries, Game Changers, and Challengers. New Jersey: John Wiley \& Sons, 2010.

[74] A. Hermann, T. Gollhardt, A.-K. Cordes, and P. Kruse, "PlanDigital: A Software Tool Supporting the Digital Transformation," in DESRIST 2021 - 16th Int. Conf. Des. Sci. Res. Inf. Syst. Technol., Kristiansand, Norway, 2021, pp. 356-361.

[75] M. Price, "Scientists Discover Upsides of Virtual Meetings," Science (80-. )., vol. 368, no. 6490, pp. 457-458, may 2020.

[76] L. Rubinger, A. Gazendam, S. Ekhtiari, N. Nucci, A. Payne, H. Johal, V. Khanduja, and M. Bhandari, "Maximizing Virtual Meetings and Conferences: A Review of Best Practices," Int. Orthop., vol. 44, no. 8, pp. 1461-1466, aug 2020.

[77] A. P. Spee and P. Jarzabkowski, "Strategy Tools as Boundary Objects," Strateg. Organ., vol. 7, no. 2, pp. 223-232, may 2009.

[78] M. Ferioli, E. Dekoninck, S. Culley, B. Roussel, and J. Renaud, "Understanding the Rapid Evaluation of Innovative Ideas in the Early Stages of Design," Int. J. Prod. Dev., vol. 12, no. 1, pp. 67-83, 2010.

[79] S. Cronholm and H. Göbel, "Guidelines Supporting the Formulation of Design Principles," in Proc. 29th Australas. Conf. Inf. Syst., Sydney, Australia, 2018.

[80] S. Gregor, L. Chandra Kruse, and S. Seidel, "Research Perspectives: The Anatomy of a Design Principle," J. Assoc. Inf. Syst., vol. 21, no. 6, pp. 1622-1652, 2020.

[81] J. Venable, J. Pries-Heje, and R. Baskerville, "FEDS: A Framework for Evaluation in Design Science Research," Eur. J. Inf. Syst., vol. 25, no. 1, pp. 77-89, 2016. 